\title{
Valor nutricional de híbridos de sorgo em diferentes estádios de maturação
}

\author{
[Nutritional value of hybrids of sorghum in different maturation stages]
}

\author{
F.S. Machado ${ }^{1}$, N.M. Rodríguez ${ }^{2}$, L.C. Gonçalves ${ }^{2}$, J.A.S. Rodrigues ${ }^{3}$, M.N. Ribas $^{2}$, \\ F.C.L. Lobato ${ }^{2}$, I.R.F.M. Veiga ${ }^{2}$, R. Guimarães Júnior ${ }^{4}$, L.G.R. Pereira ${ }^{1}$
}

\author{
${ }^{1}$ Embrapa Gado de Leite - Juiz de Fora, MG \\ ${ }^{2}$ Universidade Federal de Minas Gerais - Belo Horizonte, MG \\ ${ }^{3}$ Embrapa Milho e Sorgo - Sete Lagoas, MG \\ ${ }^{4}$ Embrapa Cerrados - Brasília, DF
}

\begin{abstract}
RESUMO
Avaliaram-se a composição bromatológica e a digestibilidade in vitro das plantas, folhas, colmos e panículas de três híbridos de sorgo (BRS 610, BR 700 e BRS 655) colhidos em três estádios de maturação (leitoso, pastoso e farináceo). O delineamento utilizado foi o inteiramente casualizado, em arranjo fatorial 3x3 (híbridos x estádios de maturação), sendo as médias comparadas pelo teste $\mathrm{SNK}(\mathrm{P}<0,05)$. Os teores de matéria seca (MS) das plantas variaram de $25,73 \%$ a $43,96 \%$ e aumentaram com a maturidade. A concentração de proteína bruta $(\mathrm{PB})$ das plantas manteve-se inalterada $(\mathrm{P}>0,05)$ entre as idades de corte para todos os híbridos. Os teores de fibra insolúvel em detergente neutro (FDN) e fibra insolúvel em detergente ácido (FDA) das plantas não foram influenciados pelo estádio de maturação. Os coeficientes de digestibilidade in vitro da MS (DIVMS) das plantas do BRS 610 não variaram com a maturidade, mas para o BR 700 e BRS 655 apresentaram redução entre o estádio leitoso e o farináceo. As variações observadas nas porcentagens de MS, PB, FDN, FDA e DIVMS das frações folha, colmo e panícula ocorreram de forma diferente entre os híbridos com o avanço da maturidade. Os híbridos BR 700 e BRS 655 devem ser ensilados no estádio leitoso, enquanto o BRS 610 pode ser colhido nos três estádios de maturação avaliados.
\end{abstract}

Palavras-chave: Sorghum bicolor, digestibilidade in vitro

\begin{abstract}
The nutritional value of the plants, leaves, stems and panicles of three hybrids of sorghum (BRS 610, BR 700 and BRS 655) at three maturation stages (milk, soft dough and flour) were evaluated. A complete randomized design was used in a factorial arrangement $3 \times 3$ (hybrids $x$ ages of cut), and the means were compared by SNK (P<0.05). Dry matter contents of the plants varied from $25.73 \%$ to $43.96 \%$ and increased with maturity. The percentage of crude protein $(C P)$ of the plants remained constant $(P>0.05)$ among cuts for all the hybrids. The values of neutral detergent fiber (NDF) and acid detergent fiber $(A D F)$ of the plants were not affected by maturation stages. The in vitro dry matter digestibility (IVDMD) of the plants of BRS 610 didn't change with maturity, but decreased between milk and floury stages for $B R 700$ and BRS 655. Differences in the percentages of DM, CP, NDF, ADF and IVDMD of the plant fractions (leaves, steam and panicle) occurred differently among hybrids with the advance of maturity. The hybrids BR 700 and BRS 655 should be ensiled at milk stage, while the BRS 610 can be harvested at the three maturation stages evaluated.
\end{abstract}

Keywords: Sorghum bicolor, in vitro digestibility

Recebido em 22 de maio de 2012

Aceito em 20 de agosto de 2013

E-mail: fernanda.machado@ embrapa.br

Apoio financeiro: CNPq e FAPEMIG 


\section{INTRODUÇÃO}

Em regiões áridas e semiáridas, a utilização do sorgo (Sorghum bicolor (L.) Moench) para produção de forragem destaca-se pela alta produtividade e valor nutricional dessa gramínea. A maturação da planta de sorgo envolve o acúmulo de constituintes da parede celular na parte vegetativa da planta e, simultaneamente, a elevação da proporção de panícula. Dessa forma, para que se possa definir o momento de colheita, é necessário conhecer o comportamento de cada híbrido em diversas condições de manejo e definir até que ponto o acúmulo de amido nos grãos compensa a diminuição na digestibilidade da parte vegetativa da planta. O objetivo deste experimento foi avaliar o valor nutricional dos híbridos BRS 610, BR 700 e BRS 655, bem como de suas frações folha, colmo e panícula, em três estádios de maturação, visando à produção de silagem.

\section{MATERIAL E MÉTODOS}

O experimento foi conduzido na Embrapa Milho e Sorgo, localizada no município de Sete Lagoas, Minas Gerais. Foram avaliados três híbridos de sorgo (BRS 610, BR 700 e BRS 655) em três idades de corte com diferentes estádios de maturação dos grãos: leitoso, pastoso e farináceo (Tab. 1).

Tabela 1. Idades de corte (dias após o plantio) dos híbridos de sorgo em cada estádio de maturação avaliado

\begin{tabular}{lccc}
\hline \multirow{2}{*}{ Híbridos } & \multicolumn{3}{c}{ Estádio de maturação } \\
\cline { 2 - 4 } & Leitoso & Pastoso & Farináceo \\
\hline BRS 610 & 100 & 108 & 114 \\
BR 700 & 100 & 108 & 114 \\
BRS 655 & 94 & 100 & 108 \\
\hline
\end{tabular}

O material foi semeado em 9 de dezembro de 2006, em canteiros constituídos por 4 fileiras com 5 metros de comprimento e 70 centímetros de espaçamento entre linhas. Foram utilizados $350 \mathrm{~kg} \mathrm{ha}^{-1}$ da fórmula 08-28-16 (N-P-K) no plantio e $100 \mathrm{~kg} \mathrm{ha}^{-1}$ de ureia como adubação de cobertura. Para o controle de plantas invasoras utilizou-se o herbicida Atrazine. Para cada híbrido foram utilizados 4 canteiros por estádio de maturação, sendo o corte realizado nas duas linhas centrais, descartando-se $2 \mathrm{~m}$ nas extremidades dos canteiros. As plantas existentes em cada canteiro foram cortadas manualmente, rente ao solo. Desse material, dez plantas foram fracionadas em colmos, folhas e panículas. Amostras da planta inteira e de suas frações foram picadas em picadeira estacionária, homogeneizadas e amostradas. Foram determinados os teores de matéria seca em estufa a $105^{\circ} \mathrm{C}$ e proteína bruta pelo método kjeldahl, segundo AOAC (Association..., 2000). As frações fibrosas foram determinadas pelo método sequencial de Van Soest et al. (1991), com adição de $2 \mathrm{~mL}$ de amilase termo resistente no aparelho Fiber analyser ANKOM ${ }^{220}$, utilizando saquinho F-57 ANKOM $^{\mathrm{R}}$. A digestibilidade in vitro da matéria seca (DIVMS) foi realizada segundo o procedimento de dois estágios descrito por Tilley e Terry (1963), adaptado por Holden (1999) para utilização do simulador de rúmen Daisy ${ }^{\mathrm{II}} \mathrm{ANKOM}^{\mathrm{R}}$.

O delineamento experimental utilizado foi inteiramente ao acaso, em esquema fatorial $3 \times 3$ (híbridos $\mathrm{x}$ idades de corte), com quatro repetições (canteiros). Os dados obtidos foram submetidos à análise de variância utilizando-se o pacote estatístico SAEG 9.1 (2007) e as médias, comparadas pelo teste SNK ao nível de $5 \%$ de probabilidade.

\section{RESULTADOS E DISCUSSÃO}

O teor de MS das folhas aumentou significativamente entre cortes sucessivos para o BRS 610 (Tab. 2). Para esse híbrido a desidratação das folhas foi mais intensa entre os estádios pastoso e farináceo $(64,6 \%)$. Entretanto, observa-se que o BR 700 sofreu desidratação intensa das folhas entre os estádios leitoso e pastoso $(75,5 \%)$ e, dessa forma, atingiu teor de MS nas folhas superior aos demais híbridos já no segundo corte. Já o BRS 655 obteve elevação menos intensa do teor de MS nas folhas, de $25,4 \%$ entre o primeiro e o terceiro corte, e apresentou valor inferior aos demais no estádio farináceo.

Pedreira et al. (2003) observaram teores de MS das folhas inferiores ao presente trabalho, entre $37,4 \%$ e $47,6 \%$ para híbridos de sorgo em cultura de safrinha, colhidos no estádio farináceo. Os valores observados também estão acima dos valores encontrados por outros autores nos estádios de grão pastoso a farináceo, entre $25 \%$ e 35\% (Neumann et al., 2002a; 2002b). 
Tabela 2. Teores médios da composição química e digestibilidade in vitro da matéria seca das folhas, de acordo com o híbrido de sorgo e estádio de maturação

\begin{tabular}{lccccc}
\hline \multirow{2}{*}{ Híbridos } & \multicolumn{5}{c}{ Parâmetros } \\
\cline { 2 - 6 } & MS $^{1}$ & PB $^{2}$ & FDN $^{3}$ & FDA $^{4}$ & DIVMS $^{5}$ \\
\hline BRS 610 & $27,50 \mathrm{Ac}$ & $9,73 \mathrm{Ba}$ & $65,40 \mathrm{Bb}$ & $36,37 \mathrm{Aa}$ & $56,80 \mathrm{Aa}$ \\
BR 700 & $33,30 \mathrm{Ab}$ & $8,82 \mathrm{Ba}$ & $70,47 \mathrm{Aa}$ & $40,95 \mathrm{Aa}$ & $50,77 \mathrm{Ba}$ \\
BRS 655 & $31,27 \mathrm{Ab}$ & $12,50 \mathrm{Aa}$ & $67,14 \mathrm{ABb}$ & $34,84 \mathrm{Aab}$ & $56,88 \mathrm{Aa}$ \\
\hline \multicolumn{7}{c}{ Pastoso } \\
\hline BRS 610 & $34,26 \mathrm{Bb}$ & $7,15 \mathrm{Bb}$ & $70,66 \mathrm{Aa}$ & $38,50 \mathrm{Aa}$ & $50,10 \mathrm{Bb}$ \\
BR 700 & $58,44 \mathrm{Aa}$ & $5,97 \mathrm{Bb}$ & $74,08 \mathrm{Aa}$ & $42,61 \mathrm{Aa}$ & $45,15 \mathrm{Ca}$ \\
BRS 655 & $31,56 \mathrm{Bb}$ & $10,79 \mathrm{Ab}$ & $64,10 \mathrm{Bb}$ & $31,95 \mathrm{Bb}$ & $54,99 \mathrm{Aa}$ \\
\hline & & Farináceo & \\
\hline BRS 610 & $56,38 \mathrm{Ba}$ & $5,73 \mathrm{Bc}$ & $74,51 \mathrm{Aa}$ & $41,98 \mathrm{Aa}$ & $50,39 \mathrm{Ab}$ \\
BR 700 & $62,18 \mathrm{Aa}$ & $4,86 \mathrm{Bb}$ & $73,97 \mathrm{Aa}$ & $43,26 \mathrm{Aa}$ & $47,62 \mathrm{Aa}$ \\
BRS 655 & $39,22 \mathrm{Ca}$ & $8,93 \mathrm{Ac}$ & $72,47 \mathrm{Aa}$ & $40,56 \mathrm{Aa}$ & $52,23 \mathrm{Aa}$ \\
\hline
\end{tabular}

Médias seguidas por letras maiúsculas iguais, na mesma coluna e no mesmo estádio de maturação, indicam igualdade estatística entre os híbridos pelo teste SNK $(\mathrm{P}>0,05)$. Letras minúsculas na mesma coluna comparam o mesmo híbrido entre os estádios de maturação, sendo que letras minúsculas iguais indicam igualdade estatística pelo teste SNK (P>0,05). MS: matéria seca; PB: proteína bruta; FDN: fibra insolúvel em detergente neutro; FDA: fibra insolúvel em detergente ácido; DIVMS: digestibilidade in vitro da matéria seca; ${ }^{1} \mathrm{CV}=8,52 \% ;{ }^{2} \mathrm{CV}=11,72 \% ;{ }^{3} \mathrm{CV}=$ $3,81 \% ;{ }^{4} \mathrm{CV}=10,64 \% ;{ }^{5} \mathrm{CV}=6,24 \%$.

Os híbridos BRS 655 e BRS 610 apresentaram reduções nos teores de $\mathrm{PB}$ das folhas entre cortes sucessivos (Tab. 2). Já o BR 700 mostrou maior teor de PB no estádio leitoso, sendo os estádios subsequentes semelhantes $(\mathrm{P}>0,05)$. Comparando-se os híbridos dentro do mesmo estádio de maturação, o BRS 655 obteve maior porcentagem de $\mathrm{PB}$ nas folhas do que os demais, que foram semelhantes $(\mathrm{P}>0,05)$, em todos os cortes. A avaliação conjunta do comportamento dos teores de PB e de MS das folhas do BRS 655 evidencia que esse híbrido se destacou pelo teor proteico da folhagem e pela eficiência na conservação do valor nutricional das folhas. Neumann et al. (2002b) encontraram valor médio de PB das folhas de híbridos de sorgo forrageiro colhidos no estádio farináceo-duro de $5,84 \%$, inferior ao observado para o BRS 655 no presente trabalho.

O BR 700 não apresentou variação significativa no teor de FDN das folhas entre as idades de corte (Tab. 2). Os demais híbridos apresentaram elevação no teor de FDN com o avanço da maturidade. Para o BRS 610 esse aumento ocorreu entre o primeiro e o segundo corte e, para o BRS 655, foi mais tardio, entre o segundo e o terceiro corte. Dessa forma, no estádio leitoso, o BR 700 apresentou maior valor de FDN nas folhas do que o BRS 610. No estádio pastoso, o BRS 610 e o BR 700 se igualaram, sendo o BRS 655 inferior a ambos. Apenas no terceiro corte não foi encontrada diferença entre os híbridos. Pedreira et al. (2003) obtiveram teores de FDN entre $67,61 \%$ e $76,81 \%$ para oito híbridos de sorgo no estádio farináceo; valores próximos aos do presente experimento.

Os híbridos BRS 610 e BR 700 não apresentaram variação nos teores de FDA das folhas entre os estádios de maturação (Tab. 2). Já o BRS 655 obteve comportamento variável para esse parâmetro, com valor superior no terceiro e inferior no segundo corte. No estádio leitoso e farináceo, não houve diferença entre os híbridos avaliados; já no estádio pastoso, o BRS 655 apresentou menor teor de FDA das folhas que os demais, que foram semelhantes entre si. Os valores obtidos por Pedreira et al. (2003) para oito híbridos de sorgo variaram entre $37,70 \%$ e $42,14 \%$, o que está de acordo com o obtido neste trabalho.

Os híbridos BR 700 e BRS 655 não apresentaram variação significativa na DIVMS das folhas com o avanço da maturidade da planta (Tab. 2). Já o BRS 610 obteve redução desse parâmetro entre o estádio leitoso e o pastoso, que foi semelhante ao estádio farináceo. No estádio leitoso o BRS 655 foi semelhante ao BRS 610, sendo ambos superiores ao BR 700. No estádio pastoso, o BRS 655 apresentou maior DIVMS do que o BRS 
610, que foi superior ao BR 700. No estádio farináceo não houve diferenças significativas entre os híbridos. Neumann et al. (2002b) encontraram valores médios de DIVMS das folhas de híbridos de sorgo forrageiro e duplopropósito de $54,85 \%$.
O teor de MS dos colmos não alterou com a maturidade da planta para todos os híbridos (Tab. 3). Comparando-se os híbridos dentro de um mesmo estádio de maturação, o BR 700 apresentou maior teor de MS no colmo do que os demais $(\mathrm{P}<0,05)$, que foram semelhantes entre si em todos os cortes.

Tabela 3. Teores médios da composição química e digestibilidade in vitro da matéria seca do colmo, de acordo com o híbrido de sorgo e estádio de maturação

\begin{tabular}{|c|c|c|c|c|c|}
\hline \multirow{2}{*}{ Híbridos } & \multicolumn{5}{|c|}{ Parâmetros } \\
\hline & $\mathrm{MS}^{1}$ & $\mathrm{~PB}^{2}$ & $\mathrm{FDN}^{3}$ & $\mathrm{FDA}^{4}$ & DIVMS $^{5}$ \\
\hline & \multicolumn{5}{|c|}{ Leitoso } \\
\hline BRS 610 & $20,71 \mathrm{Ba}$ & $2,18 \mathrm{Aa}$ & $59,33 \mathrm{Ab}$ & $37,53 \mathrm{Ab}$ & $55,00 \mathrm{Aa}$ \\
\hline BR 700 & $26,46 \mathrm{Aa}$ & $1,84 \mathrm{Aa}$ & $59,10 \mathrm{Ab}$ & $34,74 \mathrm{Ab}$ & $54,34 \mathrm{Aa}$ \\
\hline \multirow[t]{2}{*}{ BRS 655} & $22,66 \mathrm{Ba}$ & $2,19 \mathrm{Aa}$ & $60,08 \mathrm{Aa}$ & $38,97 \mathrm{Aa}$ & $52,71 \mathrm{Aa}$ \\
\hline & \multicolumn{5}{|c|}{ Pastoso } \\
\hline BRS 610 & $19,39 \mathrm{Ba}$ & $1,70 \mathrm{Ab}$ & $68,82 \mathrm{Aa}$ & $44,52 \mathrm{ABa}$ & $51,30 \mathrm{Ab}$ \\
\hline BR 700 & $26,22 \mathrm{Aa}$ & $1,62 \mathrm{Aa}$ & $71,65 \mathrm{Aa}$ & $47,61 \mathrm{Aa}$ & $46,77 \mathrm{Bb}$ \\
\hline \multirow[t]{2}{*}{ BRS 655} & $21,14 \mathrm{Ba}$ & $1,84 \mathrm{Aa}$ & $61,91 \mathrm{Ba}$ & $40,79 \mathrm{Ba}$ & $50,62 \mathrm{Aa}$ \\
\hline & \multicolumn{5}{|c|}{ Farináceo } \\
\hline BRS 610 & $19,06 \mathrm{Ba}$ & $1,59 \mathrm{Ab}$ & $74,75 \mathrm{Aa}$ & $49,12 \mathrm{Aa}$ & $46,29 \mathrm{Ac}$ \\
\hline BR 700 & $26,24 \mathrm{Aa}$ & $1,49 \mathrm{Aa}$ & $75,18 \mathrm{Aa}$ & $47,12 \mathrm{Aa}$ & $43,89 \mathrm{Ab}$ \\
\hline BRS 655 & $20,45 \mathrm{Ba}$ & $1,42 \mathrm{Ab}$ & $67,30 \mathrm{Ba}$ & $41,46 \mathrm{Ba}$ & $46,77 \mathrm{Ab}$ \\
\hline
\end{tabular}

Médias seguidas por letras maiúsculas iguais, na mesma coluna e no mesmo estádio de maturação, indicam igualdade estatística entre os híbridos pelo teste $\mathrm{SNK}(\mathrm{P}>0,05)$. Letras minúsculas na mesma coluna comparam o mesmo híbrido entre os estádios de maturação, sendo que letras minúsculas iguais indicam igualdade estatística pelo teste SNK (P>0,05). MS: matéria seca; PB: proteína bruta; FDN: fibra insolúvel em detergente neutro; FDA: fibra insolúvel em detergente ácido; DIVMS: digestibilidade in vitro da matéria seca; ${ }^{1} \mathrm{CV}=6,16 \% ;{ }^{2} \mathrm{CV}=16,12 \% ;{ }^{3} \mathrm{CV}=$ $6,30 \% ;{ }^{4} \mathrm{CV}=8,28 \% ;{ }^{5} \mathrm{CV}=4,79 \%$.

Os híbridos apresentaram valores de $\mathrm{PB}$ do colmo semelhantes entre si em todos os cortes (P>0,05) (Tab. 3). Os teores de PB do colmo foram influenciados pelo estádio de maturação para os híbridos BRS 610 e BRS 655, que apresentaram valores mais baixos no terceiro corte em relação ao primeiro $(\mathrm{P}<0,05)$. Já o BR 700 não apresentou variação nesse parâmetro com o avanço da maturidade da planta.

Os colmos dos híbridos BRS 610 e BR 700 apresentaram aumento do teor de FDN e FDA entre os estádios leitoso e pastoso e estabilização no corte posterior (Tab. 3). Entretanto, o aumento para o BRS 610 foi de $15,9 \%$ para FDN e $18,6 \%$ para FDA, ao passo que, para o BR 700, foi de $21,2 \%$ para FDN e $37 \%$ para FDA. Já o BRS 655 não apresentou variação nos teores de FDN e FDA do colmo entre as idades de corte. Dessa forma, no estádio leitoso não houve diferença entre os híbridos. já no estádio farináceo, o BRS 655 apresentou menor teor de FDN e FDA que os demais híbridos $(\mathrm{P}<0,05)$, que foram semelhantes entre si $(\mathrm{P}>0,05)$.
Pedreira et al. (2003) obtiveram teores de FDN e FDA dos colmos de oito híbridos de sorgo, entre $49,43 \%$ e $68,05 \%$ e entre $29,30 \%$ e $39,36 \%$, respectivamente, para o estádio farináceo, valores inferiores aos do presente trabalho.

O híbrido BRS 610 apresentou redução gradativa da DIVMS do colmo entre cortes sucessivos (Tab. 3). Já o BR 700 apresentou redução na digestibilidade entre os estádios leitoso e pastoso, enquanto para o BRS 655, a queda na DIVMS do colmo ocorreu mais tardiamente, entre os estádios pastoso e farináceo. No primeiro e no terceiro cortes não houve diferença ( $>>0,05)$ entre os híbridos avaliados. Já no estádio pastoso o BR 700 apresentou menor teor de DIVMS do que os demais, que foram semelhantes entre si.

De acordo com Pedreira et al. (2003), para reduzir perdas de qualidade na planta, têm-se selecionado cultivares que apresentam a característica "stay green", ou seja, o colmo se mantém verde por tempo mais prolongado. 
Neumann et al. (2002b) encontraram valores médios de DIVMS do colmo de $60,1 \%$ para híbridos de sorgo forrageiro (estádio farináceoduro) e 54,3\% para híbridos de sorgo duplopropósito (estádio pastoso-farináceo), valores superiores aos do presente estudo.

O teor de MS das panículas aumentou gradativamente com a maturidade das plantas para todos os híbridos (Tab. 4). No estádio leitoso os híbridos apresentaram teor de MS na panícula semelhante entre si. No estádio pastoso o BR 700 apresentou maior teor de MS na panícula do que os demais; entretanto, no estádio farináceo não houve diferença entre o BR 700 e o BRS 610. Já o BRS 655 apresentou o menor teor de MS nos estádios pastoso e farináceo. Os acúmulos de MS nas panículas entre o primeiro e o terceiro corte foram de 54,05\%, 49,12\% e $46,25 \%$ para o BRS 610, BR 700 e BRS 655, respectivamente.

Tabela 4. Teores médios da composição química e digestibilidade in vitro da matéria seca da panícula, de acordo com o híbrido de sorgo e estádio de maturação

\begin{tabular}{|c|c|c|c|c|c|}
\hline \multirow{2}{*}{ Híbridos } & \multicolumn{5}{|c|}{ Parâmetros } \\
\hline & $\mathrm{MS}^{1}$ & $\mathrm{~PB}^{2}$ & $\mathrm{FDN}^{3}$ & $\mathrm{FDA}^{4}$ & DIVMS $^{5}$ \\
\hline & \multicolumn{5}{|c|}{ Leitoso } \\
\hline BRS 610 & $39,11 \mathrm{Ac}$ & $8,81 \mathrm{Ba}$ & $41,25 \mathrm{Aa}$ & $21,20 \mathrm{Aa}$ & $58,88 \mathrm{Bb}$ \\
\hline BR 700 & $41,33 \mathrm{Ac}$ & $9,24 \mathrm{ABa}$ & $31,77 \mathrm{Ba}$ & $15,07 \mathrm{Ba}$ & $62,85 \mathrm{Aa}$ \\
\hline \multirow[t]{2}{*}{ BRS 655} & $38,96 \mathrm{Ac}$ & $9,64 \mathrm{Aa}$ & $41,94 \mathrm{Aa}$ & $23,43 \mathrm{Aa}$ & $55,49 \mathrm{Cc}$ \\
\hline & \multicolumn{5}{|c|}{ Pastoso } \\
\hline BRS 610 & $54,34 \mathrm{Bb}$ & $8,26 \mathrm{Ba}$ & $26,29 \mathrm{Ab}$ & $11,29 \mathrm{Bb}$ & $67,73 \mathrm{Aa}$ \\
\hline BR 700 & $58,00 \mathrm{Ab}$ & $8,51 \mathrm{ABb}$ & $26,62 \mathrm{Ab}$ & $12,75 \mathrm{Ba}$ & $65,13 \mathrm{Ba}$ \\
\hline \multirow[t]{2}{*}{ BRS 655} & $45,43 \mathrm{Cb}$ & $8,97 \mathrm{Ab}$ & $31,01 \mathrm{Ab}$ & $16,90 \mathrm{Ab}$ & $59,76 \mathrm{Cb}$ \\
\hline & \multicolumn{5}{|c|}{ Farináceo } \\
\hline BRS 610 & $60,25 \mathrm{Aa}$ & $8,31 \mathrm{Ba}$ & $22,01 \mathrm{Ab}$ & $8,55 \mathrm{Bb}$ & $69,50 \mathrm{Aa}$ \\
\hline BR 700 & $61,63 \mathrm{Aa}$ & $7,95 \mathrm{Bc}$ & $25,15 \mathrm{Ab}$ & $12,05 \mathrm{Aa}$ & $65,08 \mathrm{Ba}$ \\
\hline BRS 655 & $56,98 \mathrm{Ba}$ & $8,91 \mathrm{Ab}$ & $26,70 \mathrm{Ab}$ & $13,91 \mathrm{Ac}$ & $62,32 \mathrm{Ca}$ \\
\hline
\end{tabular}

Médias seguidas por letras maiúsculas iguais, na mesma coluna e no mesmo estádio de maturação, indicam igualdade estatística entre os híbridos pelo teste SNK $(\mathrm{P}>0,05)$. Letras minúsculas na mesma coluna comparam o mesmo híbrido entre os estádios de maturação, sendo que letras minúsculas iguais indicam igualdade estatística pelo teste SNK (P>0,05). MS: matéria seca; PB: proteína bruta; FDN: fibra insolúvel em detergente neutro; FDA: fibra insolúvel em detergente ácido; DIVMS: digestibilidade in vitro da matéria seca; ${ }^{1} \mathrm{CV}=4,37 \% ;{ }^{2} \mathrm{CV}=4,25 \%$; ${ }^{3} \mathrm{CV}=$ $11,65 \% ;{ }^{4} \mathrm{CV}=13,02 \% ;{ }^{5} \mathrm{CV}=2,42 \%$.

Neumann et al. (2002b), avaliando híbridos de sorgo, encontraram teores de MS nas panículas variando de $45,7 \%$ a $55,7 \%$, quando estas se encontravam no estádio de grão pastoso a farináceo; valores inferiores aos observados no presente trabalho.

Com relação ao teor de $\mathrm{PB}$ das panículas, o híbrido BRS 655 apresentou maior valor no estádio leitoso do que nos estádios pastoso e farináceo, que foram semelhantes entre si (Tab. 4). Já o BRS 610 não apresentou alteração na porcentagem de PB das panículas com o avanço da maturidade, enquanto para o BR 700 ocorreu redução significativa entre cortes sucessivos. Os teores de PB na panícula obtidos por Neumann et al. (2002b) e Pedreira et al. (2003) variaram de $6,8 \%$ a $7,0 \%$ e $6,5 \%$ a $7,7 \%$, respectivamente.
Todos os híbridos apresentaram redução no teor de FDN da panícula entre o estádio leitoso e o pastoso, sendo este último semelhante ao farináceo (Tab. 4). A queda na porcentagem de FDN nas panículas entre o primeiro e o terceiro corte se deve ao acúmulo de amido nos grãos, com consequente diluição das frações fibrosas nessa fração da planta. Entretanto, entre o segundo e o terceiro corte, a ausência de alteração significativa no teor de FDN indica que o aumento da quantidade de amido nos grãos não superou uma possível elevação do teor de FDN da haste da panícula. Além disso, pode ter ocorrido perda de grãos no estádio farináceo por ataque de pássaros ou queda natural. No primeiro corte, o BR 700 obteve menor valor de FDN que os demais híbridos, que foram semelhantes $(\mathrm{P}>0,05)$. Nos cortes subsequentes, não foram observadas diferenças entre os materiais 
avaliados. O menor teor de FDN na panícula do BR 700 no primeiro corte indica que esse híbrido apresentou maior translocação de nutrientes para os grãos ainda no estádio leitoso. Assim, a queda no teor de FDN entre o primeiro e o segundo corte foi menos acentuada para esse híbrido $(16,2 \%)$. Já para os demais híbridos, a redução do teor de FDN da panícula nesse intervalo foi mais intensa $(36,3 \%$ para o BRS 610 e 26,1\% para o BRS 655). Os teores de FDN das panículas de oito híbridos de sorgo avaliados por Pedreira et al. (2003) no estádio farináceo variaram de $46,8 \%$ a $55,5 \%$; valores bem superiores aos encontrados no presente trabalho.

O híbrido BRS 610 apresentou redução no teor de FDA da panícula entre o estádio leitoso e o pastoso, com estabilização no corte posterior (Tab. 4). O BR 700 não mostrou influência do estádio de maturação sobre esse parâmetro. Já o BRS 655 obteve reduções no teor de FDA entre cortes sucessivos. Comparando-se os híbridos em cada estádio, no primeiro corte o BR 700 obteve menor teor de FDA na panícula que os outros materiais, que foram semelhantes entre si. Devido à redução de $46,75 \%$ no teor de FDA do BRS 610 entre o primeiro e o segundo corte, no estádio pastoso esse híbrido igualou-se ao BR 700; já o BRS 655 apresentou o maior valor. No estádio farináceo o BRS 610 passou a apresentar o menor teor de FDA em relação aos demais híbridos. O menor teor de FDA na panícula do híbrido BR 700 no estádio leitoso indica o maior acúmulo de amido nos seus grãos em relação aos outros híbridos, o que também foi evidenciado pelo teor de FDN. Dessa forma, enquanto o BR 700 apresentou valores constantes de FDA na panícula entre os estádios avaliados, o BRS 610 e BRS 655 mostraram queda acentuada desse parâmetro com o avanço da maturidade da planta.

O híbrido BRS 655 mostrou aumento gradativo na DIVMS da panícula (Tab. 4). Já o BRS 610 apresentou DIVMS inferior no primeiro corte, sendo os cortes subsequentes semelhantes $(P>0,05)$. Não houve alteração na DIVMS da panícula do BR 700 com o avanço da maturidade da planta. No estádio leitoso observa-se maior DIVMS para a panícula do BR 700, o que sugere maior acúmulo de amido nos grãos para esse híbrido. Nos estádios pastoso e farináceo o BRS 610 passa a apresentar maior DIVMS na panícula do que os demais híbridos. O BRS 655 mostra-se inferior aos demais híbridos em todos os cortes. Os maiores valores de DIVMS da panícula do BRS 610 nos dois últimos cortes podem estar relacionados à ausência de tanino nesse material, enquanto os outros híbridos são classificados como variedades com tanino. Neumann et al. (2002b) encontraram valores médios de DIVMS da panícula de híbridos de sorgo forrageiro e duplo-propósito de 68,20\%.

A porcentagem de MS da planta do híbrido BRS 610 foi menor no primeiro corte, sendo os dois últimos cortes semelhantes $(\mathrm{P}>0,05)$ (Tab. 5). Já os teores de MS do BR 700 aumentaram entre cortes sucessivos. Observa-se, portanto, um aumento considerável, de $34,4 \%$, no teor de MS desse híbrido entre o primeiro e o segundo corte. Já o BRS 655 apresentou teores de MS semelhantes entre os dois primeiros cortes e superior no terceiro corte.

Na comparação entre híbridos dentro das épocas de corte, verifica-se que o BR 700 apresentou maior teor de MS da planta que os demais em todos os cortes. Além disso, esse híbrido apresentou maior acúmulo de MS, de 48,16\%, entre o primeiro e o terceiro corte, enquanto o BRS 610 e BRS 655 mostraram acúmulos de MS de $17,7 \%$ e $15,5 \%$, respectivamente.

Segundo Silva et al. (1999), os teores de MS dos componentes da planta são variáveis conforme a interação genótipo-ambiente, atuando sobre o acúmulo de MS da planta inteira. Das frações da planta de sorgo, o colmo é a porção que menos contribui para a elevação do teor de matéria seca, seguido pelas folhas e a panícula; esta última permitindo grandes ganhos de matéria seca em um curto período (Johnson et al., 1971; Zago, 1991). Neumann et al. (2002b) avaliaram híbridos de sorgo forrageiro (estádio farináceoduro) e de duplo-propósito (estádio pastosofarináceo) e encontraram valores médios de $28,46 \%, 30,01 \%$ e $49,99 \%$ para os teores de MS do colmo, folha e panícula. No presente trabalho, foram observadas correlações $(\mathrm{P}<0,05)$ dos teores de MS da planta com o teor de MS das folhas $(\mathrm{r}=0,82)$ e com o teor de MS da panícula $(\mathrm{r}=0,69)$. Também houve correlação $(\mathrm{P}<0,05)$ entre os teores de MS da planta e do colmo $(\mathrm{r}=$ $0,60)$, o que contribuiu para que a planta do BR 700 apresentasse maior teor de MS do que os demais híbridos, os quais apresentaram maior umidade nos colmos. 
Tabela 5. Teores médios da composição química e digestibilidade in vitro da matéria seca da planta inteira, de acordo com o híbrido de sorgo e estádio de maturação

\begin{tabular}{|c|c|c|c|c|c|}
\hline \multirow{2}{*}{ Híbridos } & \multicolumn{5}{|c|}{ Parâmetros } \\
\hline & $\mathrm{MS}^{1}$ & $\mathrm{~PB}^{2}$ & $\mathrm{FDN}^{3}$ & $\mathrm{FDA}^{4}$ & DIVMS $^{5}$ \\
\hline & \multicolumn{5}{|c|}{ Leitoso } \\
\hline BRS 610 & $25,73 \mathrm{Bb}$ & $6,07 \mathrm{Aa}$ & $57,18 \mathrm{Aa}$ & 33,37Aa & $55,43 \mathrm{Aa}$ \\
\hline BR 700 & $29,67 \mathrm{Ac}$ & $5,65 \mathrm{Aa}$ & $57,41 \mathrm{Aa}$ & $35,06 \mathrm{Aa}$ & $55,90 \mathrm{Aa}$ \\
\hline \multirow[t]{2}{*}{ BRS 655} & $26,99 \mathrm{Bb}$ & $6,26 \mathrm{Aa}$ & $54,73 \mathrm{Aa}$ & $33,41 \mathrm{Aa}$ & $55,92 \mathrm{Aa}$ \\
\hline & \multicolumn{5}{|c|}{ Pastoso } \\
\hline BRS 610 & $28,69 \mathrm{Ba}$ & $5,82 \mathrm{Aa}$ & $55,22 \mathrm{Aa}$ & $32,16 \mathrm{Aa}$ & $56,13 \mathrm{Aa}$ \\
\hline BR 700 & $39,87 \mathrm{Ab}$ & $5,21 \mathrm{Aa}$ & $56,62 \mathrm{Aa}$ & $34,75 \mathrm{Aa}$ & $52,75 \mathrm{Bb}$ \\
\hline \multirow[t]{2}{*}{ BRS 655} & $27,39 \mathrm{Bb}$ & $6,08 \mathrm{Aa}$ & $54,02 \mathrm{Aa}$ & $33,45 \mathrm{Aa}$ & $54,04 \mathrm{ABab}$ \\
\hline & \multicolumn{5}{|c|}{ Farináceo } \\
\hline BRS 610 & $30,28 \mathrm{Ba}$ & 5,32Aa & $56,67 \mathrm{Aa}$ & $33,60 \mathrm{Aa}$ & $54,12 \mathrm{Aa}$ \\
\hline BR 700 & 43,96Aa & $5,49 \mathrm{Aa}$ & $57,21 \mathrm{Aa}$ & $33,09 \mathrm{Aa}$ & $53,60 \mathrm{Ab}$ \\
\hline BRS 655 & $31,17 \mathrm{Ba}$ & $6,15 \mathrm{Aa}$ & $53,03 \mathrm{Ba}$ & $32,26 \mathrm{Aa}$ & $53,04 \mathrm{Ab}$ \\
\hline
\end{tabular}

Médias seguidas por letras maiúsculas iguais, na mesma coluna e no mesmo estádio de maturação, indicam igualdade estatística entre os híbridos pelo teste SNK $(\mathrm{P}>0,05)$. Letras minúsculas na mesma coluna comparam o mesmo híbrido entre os estádios de maturação, sendo que letras minúsculas iguais indicam igualdade estatística pelo teste SNK ( $\mathrm{P}>0,05)$. MS: matéria seca; PB: proteína bruta; FDN: fibra insolúvel em detergente neutro; FDA: fibra insolúvel em detergente ácido; DIVMS: digestibilidade in vitro da matéria seca; ${ }^{1} \mathrm{CV}=4,17 \% ;{ }^{2} \mathrm{CV}=9,37 \% ;{ }^{3} \mathrm{CV}=$ $3,37 \% ;{ }^{4} \mathrm{CV}=4,62 \% ;{ }^{5} \mathrm{CV}=2,82 \%$.

Na comparação entre híbridos dentro das épocas de corte, verifica-se que o BR 700 apresentou maior teor de MS da planta que os demais em todos os cortes. Além disso, esse híbrido apresentou maior acúmulo de MS, de 48,16\%, entre o primeiro e o terceiro corte, enquanto o BRS 610 e BRS 655 mostraram acúmulos de MS de $17,7 \%$ e $15,5 \%$, respectivamente.

Segundo Silva et al. (1999), os teores de MS dos componentes da planta são variáveis conforme a interação genótipo-ambiente, atuando sobre o acúmulo de MS da planta inteira. Das frações da planta de sorgo, o colmo é a porção que menos contribui para a elevação do teor de matéria seca, seguido pelas folhas e a panícula; esta última permitindo grandes ganhos de matéria seca em um curto período (Johnson et al., 1971; Zago, 1991). Neumann et al. (2002b) avaliaram híbridos de sorgo forrageiro (estádio farináceoduro) e de duplo-propósito (estádio pastosofarináceo) e encontraram valores médios de $28,46 \%, 30,01 \%$ e $49,99 \%$ para os teores de MS do colmo, folha e panícula. No presente trabalho, foram observadas correlações $(\mathrm{P}<0,05)$ dos teores de MS da planta com o teor de MS das folhas $(\mathrm{r}=0,82)$ e com o teor de MS da panícula $(\mathrm{r}=0,69)$. Também houve correlação $(\mathrm{P}<0,05)$ entre os teores de MS da planta e do colmo ( $\mathrm{r}=$ $0,60)$, o que contribuiu para que a planta do BR 700 apresentasse maior teor de MS do que os demais híbridos, os quais apresentaram maior umidade nos colmos.

As porcentagens de $\mathrm{PB}$ das plantas inteiras mantiveram-se inalteradas entre as idades de corte para todos os híbridos (Tab. 5). Comparando-se os híbridos dentro de cada estádio de maturação, observaram-se teores de proteína semelhantes entre os híbridos. Araújo et al. (2007) também não observaram alteração na porcentagem de proteína com a maturidade da planta do híbrido BR 700, sendo o valor médio de $7,64 \%$.

A correlação entre teores de $\mathrm{PB}$ da planta e da panícula não foi significativa $(\mathrm{P}>0,05)$. Contudo, houve significância $(\mathrm{P}<0,05)$ para as correlações do teor proteico da planta com o das folhas $(\mathrm{r}=$ $0,57)$ e do colmo $(r=0,60)$.

Na planta, os teores de FDN não variaram significativamente entre estádios de maturação, para todos os híbridos avaliados (Tab. 5). A estabilidade dos níveis de FDN das plantas inteiras com o avanço do estádio de maturação pode estar relacionada ao aumento da participação da panícula e redução da participação do colmo. Comparando-se os híbridos em um mesmo corte, nos estádios leitoso e pastoso não houve diferenças entre eles; já no estádio farináceo, o BRS 655 apresentou 
menor teor de FDN que os demais híbridos, que foram semelhantes entre si. Tonani et al. (2001) e Noguera et al. (2005), avaliando híbridos de sorgo, não observaram alterações nos teores de FDN com o avanço do estádio de maturação, de grãos leitosos a farináceos. Esses autores encontraram valores médios de FDN de $60,6 \%$ e $75,7 \%$, respectivamente, sendo todos superiores aos obtidos no presente trabalho.

Os teores de FDA da planta não variaram entre as idades de corte para todos os híbridos e, comparando-se os híbridos dentro de um mesmo período, não foram observadas diferenças entre eles (Tab. 5). Dessa forma, as frações colmo, folha e panícula interagiram de maneira a manter constantes os valores dos constituintes da parede celular da planta. O comportamento do teor de FDA observado neste trabalho está de acordo com os resultados obtidos por Tonani et al. (2001) e Noguera et al. (2005), que também não encontraram variações nos teores de FDA com o avanço do estádio de maturação da planta. Esses autores encontraram teores médios de $37,44 \%$ e $39,18 \%$, respectivamente; valores superiores aos observados neste experimento.

A DIVMS da planta inteira foi semelhante entre as idades de corte para o BRS 610, ao passo que, para o BR 700, foi observada redução da DIVMS entre o primeiro e o segundo corte (Tab. 5). O BRS 655 apresentou maior $(\mathrm{P}<0,05)$ DIVMS no estádio leitoso do que no farináceo, e valor intermediário no estádio pastoso. Comparando-se os híbridos no mesmo estádio de maturação, observou-se que no estádio leitoso e farináceo não houve diferença $(\mathrm{P}>0,05)$. Já no estádio pastoso, o BRS 610 apresentou DIVMS superior ao BR 700, sendo o BRS 655 intermediário e semelhante aos demais. Pereira et al. (1993), avaliando híbridos de sorgo de porte alto (AG2002), médio (AG-2004) e baixo (AG-2005E), observaram coeficientes de DIVMS de 53,2\%, $50,8 \%$ e $54,3 \%$, respectivamente. Já Pesce et al. (2000), trabalhando com 20 genótipos de sorgo colhidos no estádio pastoso, encontraram coeficientes de DIVMS superiores para os híbridos AG-2005E (60,0\%) e AG-2002 $(57,3 \%)$, comparados aos resultados do presente trabalho. Por outro lado, Araújo et al. (2007) encontraram valores inferiores para o BR 700 (52,26\%), valores semelhantes para o BR 701 $(54,32 \%)$ e valores superiores para o Massa 03 $(58,09 \%)$.

No presente trabalho, os valores de digestibilidade das frações da planta variaram de $45,15 \%$ a $56,88 \%, 43,89 \%$ a $55,0 \%$ e $55,49 \%$ a $69,50 \%$ para as folhas, colmo e panícula, respectivamente. Apesar da maior digestibilidade da panícula, não foi observada correlação significativa $(\mathrm{P}>0,05)$ entre a DIVMS da planta e da panícula; o que pode ser explicado pela queda da qualidade da parte vegetativa da planta à medida que a participação da panícula aumentou na planta.

Os resultados apresentados no presente trabalho demostram a variabilidade dentro de cada componente da planta entre diferentes híbridos e estádios de maturação, sugerindo a possibilidade de melhoria da qualidade da silagem através da obtenção de genótipos com maiores teores de proteína e digestibilidade nas partes da planta, bem como através da determinação do momento de colheita mais adequado. O híbrido BR 700 deve ser colhido no estádio leitoso para ensilagem, devido aos elevados teores de MS e menores coeficientes de DIVMS apresentados nos estádios subsequentes. O BRS 610 apresentou período de colheita mais amplo, com teor de matéria seca adequado para ensilagem nos estádios leitoso, pastoso e farináceo, e ausência de alterações nos valores de proteína bruta, digestibilidade in vitro da matéria seca e frações fibrosas da planta inteira com o avanço da idade de corte. Já o BRS 655 apresentou teor de MS adequado para ensilagem nos três estádios de maturação avaliados, mas deve ser colhido no estádio leitoso devido à maior DIVMS observada em relação ao estádio farináceo.

\section{CONCLUSÕES}

Para produção de silagem, os híbridos BR 700 e BRS 655 devem ser colhidos no estádio leitoso. Já o BRS 610 apresenta período de colheita mais amplo. 


\section{REFERÊNCIAS}

ARAÚJO, V.L., RODRIGUEZ, N.M.; GONÇALVES, L.C. et al. Qualidade das silagens de três híbridos de sorgo ensilados em cinco diferentes estádios de maturação. Arq. Bras. Med. Vet. Zootec., v.59, p.168-174, 2007

ASSOCIATION of official analytical chemists international. Official methods of analysis. Gaithersburg: AOAC, 2000, 17.ed, v.1, 2000.

HOLDEN, L.A. Comparison of methods of in vitro dry matter digestibility for ten feeds. $J$. Dairy Sci., v.82, p.1791-1794, 1999.

JOHNSON, R. R., FARIA, V. P. McCLURE, R. E. Effects of maturity on chemical composition and digestibility of bird resistant sorghum plants when fed to sheeps on silages. Journaul of An. Sci., v.33, n.5, p.1102-1109, 1971

NEUMANN, M.; RESTLE, J.; ALVES FILHO, D.C. et al. Avaliação do valor nutritivo da planta e da silagem de diferentes híbridos de sorgo (Sorghum bicolor (L.) Moench). Rev. Bras. de Zootec., v.31, p.293-301, 2002a.

NEUMANN, M.; RESTLE, J.; ALVES FILHO, D.C. et al. Avaliação de diferentes híbridos de sorgo (Sorghum bicolor (L.) Moench) quanto aos componentes da planta e silagens produzidas. Rev. Bras. de Zootec., v.31, p.302-312, 2002 b.

NOGUERA, R.R.; SALIBA, E.O.; GONÇALVES, L.C.; MAURICIO, R.M. Utilização da técnica de produção de gás para determinar a cinética de fermentação dos carboidratos estruturais e não estruturais em sorgo para forragem. Liv. Rese. for Rural Develop., v.17, p.13, 2005.

PEDREIRA, M.S.; REIS, R.A.; BERCHIELI, T.T. et al. Características agronômicas e composição química de oito híbridos de sorgo (Sorghum bicolor (L.) Moench). Rev. Bras. Zootec, v.32, p.1083-1092, 2003.
PEREIRA, O.G.; OBEID, J.A.; GOMIDE, J.A. et al. Produtividade de uma variedade de milho (Zea mays L.) e de três variedades de sorgo (Sorghum bicolor (L.) Moench) e o valor nutritivo de suas silagens. Rev. Bras. Zootec, v.22, p.31-38, 1993.

PESCE, D.M.C.; GONÇALVES, L.C.G.; RODRÍGUEZ, N.M. Porcentagem, perda e digestibilidade in vitro da matéria seca das silagens de 20 genótipos de sorgo. Arq. Bras. Med. Vet. Zootec., v.52, p.250-255, 2000.

SAEG. SAEG: sistema para análises estatísticas, versão 9.1. Viçosa: UFV, 2007.

SILVA, F.F.; GONÇALVES, L.C.; RODRIGUES, J.A.S. et al. Qualidade de silagens de híbridos de sorgo (Sorghum bicolor (L.) Moench) de portes baixo, médioe alto com diferentes proporções de colmo+folha/panícula 1. Avaliação do valor nutritivo. Rev. Bras. Zootec, v.28, p.21-29, 1999.

TILLEY, J.M.A.; TERRY, R.A. A two-stage technique for the "in vitro" digestion of forage crops. J. Br. Grassl. Soc., v.18, p.104-111,1963.

TONANI, F.L.; RUGGIERI, A.C.; QUEIROZ, A.C; ANDRADE, P. Degradabilidade ruminal in situ da matéria seca e da fibra em detergente neutro em silagens de híbridos de sorgo colhidos em diferentes épocas. Arq. Bras. Med. Vet. Zootec., v.53, p.100-104, 2001.

VAN SOEST, P.J.; ROBERTSON, J.B.; LEWIS, B.A. Methods for dietary fiber and nonstarch polysaccaridies in relation to animal nutrition. $J$. Dairy Sci., v.74, p.3583-3597, 1991.

ZAGO, C.P. Cultura do sorgo para produção de silagem de alto valor nutritivo. In: SIMPÓSIO SOBRE NUTRIÇÃO DE BOVINOS, 4., 1991, Piracicaba. Anais... Piracicaba: FEALQ, 1991. p.169-218. 